\title{
Crandall syndrome
}

INSERM

\section{Source}

INSERM. (1999). Orphanet: an online rare disease and orphan drug data base. Crandall syndrome. ORPHA:202

Crandall syndrome is characterized by progressive sensorineural deafness, alopecia and hypogonadism with LH and GH deficiencies. It has been described in three brothers. It resembles Björnstad's syndrome (see this term) that combines irregular pili torti and deafness. It is probably inherited as and autosomal recessive disorder. 